\title{
Karakterisasi Morfologi dan Kandungan Minyak Atsiri Beberapa Jenis Sirih (Piper sp.)
}

\author{
Yuli Widiyastuti ${ }^{1}$, Sari Haryanti ${ }^{1}$, dan Dyah Subositi ${ }^{1}$ \\ ${ }^{1}$ Balai Besar Litbang Tanaman Obat dan Obat Tradisional \\ Badan Litbang Kesehatan, Kementerian Kesehatan RI \\ email: ywidiyasis@gmail.com
}

\begin{abstract}
Piper is one of the genera in the family of Piperaceae which includes more than a thousand species of plants spread in the tropics and sub-tropics. Betel (Piper betle L.) is one of the species in the genus of Piper which are common known by the public, because it is not only used as herb, but also have a significant value in the culture or custom. Based on the shape and leaf color, flavor and aroma, there are knowm some kind of betel such as worm betel, Java betel, ivory betel, Banda betel, and cloves betel. So, it will carried out the study on morphological characterization and essential oil content of some types of betel from several regions. Research conducted by taking specimens of several types of betel, and then identify the morphological characterization in the Laboratory of Plant Systematics. Analysis of essential oil performed by stahl distillation and identification of the essential oil content by Thin Layer Chromatography using Silikagel G as stationary phase and mobile phase with toluene: etyl acetate: 93: 7, visualization using vanillin sulfuric acid. The results showed that there are several types of betel known as ivory betel, worms betel, and green betel with the botanical name of Piper betle L., and red betel with botanical name of Piper crocatum L. or Piper ornatum L. Most prominent morphological differences among the betle are in the form of leaves, leaf texture, stem color, petiole color, habitus, and aroma. Essential oil content of each type of betel are as follows: green betel $(0.6 \%)$, betel worms $(0.3 \%)$, betel ivory $(0.3 \%)$, and red betel (0.6\%). TLC profile of the essential oil of each type of betel shows the differences in the number and colors of the spots.
\end{abstract}

Key words: betle leaves, morphologycal character, essensial oil.

\begin{abstract}
Abstrak
Piper merupakan salah satu marga dalam famili Piperaceae yang meliputi lebih dari seribu jenis tumbuhan yang tersebar di daerah tropis dan sub tropis. Sirih (Piper betle L.) adalah salah satu spesies dalam genus Piper yang sangat dikenal masyarakat, karena tidak hanya dimanfaatkan sebagai herbal namun juga memiliki nilai penting dalam kultur atau budaya masyarakat. Berdasarkan bentuk dan warna daun, rasa dan aroma, dikenal beberapa jenis sirih antara lain sirih cacing, sirih Jawa, sirih gading, sirih banda, dan sirih cengkih. Untuk itu dilakukan penelitian karakterisasi morfologi dan kandungan minyak atsiri beberapa jenis sirih yang berasal dari beberapa daerah. Penelitian dilakukan secara eksploratif dengan mengambil spesimen beberapa jenis sirih, kemudian dilakukan karakterisasi morfologi di Laboratorium Sistematika Tumbuhan. Analisis minyak atsiri dilakukan secara stahl destilasi dan identifikasi kandungan minyak atsiri secara Kromatografi Lapis Tipis menggunakan fase diam Silikagel G dan fase bergerak toluene:etyl acetat: 93:7, visualisasi
\end{abstract}


menggunakan vanillin asam sulfat. Hasil penelitian menunjukkan bahwa terdapat beberapa jenis sirih yang dikenal dengan nama daerah sirih gading, sirih cacing, dan sirih hijau dengan nama botani Piper betle L., serta sirih merah dengan nama botani Piper crocatum L. atau Piper ornatum L. Perbedaan morfologi yang paling menonjol ada pada bentuk daun, tekstur daun, warna batang, warna tangkai daun, habitus, dan aroma. Kadar minyak atsiri masing-masing jenis sirih berturut turut: sirih hijau $(0,6 \%)$, sirih cacing $(0,3 \%)$, sirih gading $(0,3 \%)$, dan sirih merah $(0,6 \%)$. Profil KLT dari minyak atsiri masing-masing jenis sirih menunjukkan perbedaan dalam jumlah spot maupun warna spot.

Kata kunci: sirih, karakterisasai morfologi, minyak atsiri.

\section{Pendahuluan}

Piper merupakan salah satu marga dalam famili Piperaceae yang meliputi lebih dari seribu jenis tumbuhan yang tersebar di daerah tropis dan sub tropis. ${ }^{1}$ Sirih (Piper betle L.) adalah salah satu spesies dalam genus Piper yang sangat dikenal masyarakat, karena tidak hanya dimanfaatkan sebagai herbal namun juga memiliki nilai penting dalam kultur atau budaya masyarakat. ${ }^{2}$ Secara tradisional daun sirih digunakan untuk antiradang, antiseptik, antibakteri, penghenti pendarahan, pereda batuk, peluruh kentut, perangsang keluarnya air liur, pencegah kecacingan, penghilang gatal, dan penenang. ${ }^{3}$

Tanaman ini memiliki perawakan berupa semak berkayu di bagian pangkal, merambat atau memanjat, panjang tanaman dapat mencapai $15 \mathrm{~m}$. Batang berbentuk silindris, berbuku-buku nyata, beralur, batang muda berwarna hijau, tua berwarna coklat muda. Daun tunggal, letak berseling, helaian daun berbentuk bulat telur sampai lonjong, pangkal daun berbentuk jantung atau membulat, panjang 5-18 cm, lebar daun 2,5-10,75 $\mathrm{cm}$. Perbungaan berupa bunga majemuk untai, daun pelindung kurang lebih $1 \mathrm{~mm}$, berkelamin jantan, betina atau banci. Buah batu, bulat, dan berwarna hijau keabu-abuan, tebal $1-1,5 \mathrm{~cm}$, biji agak membulat, panjang $3,5-5 \mathrm{~mm} .{ }^{4}$

Daun sirih mengandung minyak atsiri $0,8-1,8 \%$ yang terdiri atas kavikol, kavibetol (betel fenol), alilpirokatekol (hidroksikavikol). Kandungan senyawa lain adalah alilpirokatekol mono dan diasetat, karvakrol, eugenol, eugenol metileter, p-simen, sineol, kariofilen, kadinen, estragol, terpen, seskuiterpen, fenilpropan, tanin, karoten, tiamin, riboflavin, asam nikotianat, vitamin $\mathrm{C}$, gula, pati, dan asam amino. Kavikol menyebabkan sirih berbau khas dan memiliki khasiat antibakteri lima kali lebih kuat daripada fenol serta imunomodulator ${ }^{[3]}$. Daun sirih secara tradisional digunakan sebagai antiradang, antiseptik, antibakteri, penghenti pendarahan, pereda batuk, peluruh kentut, perangsang keluarnya air liur, pencegah kecacingan, penghilang gatal, dan penenang. ${ }^{3}$

Sirih dapat tumbuh pada berbagai jenis tanah. Pertumbuhan optimal tanaman sirih diperoleh pada ketinggian 10-300 m dpl. Curah hujan merupakan faktor yang menentukan untuk pertumbuhan sirih. Sirih tidak tahan terhadap genangan dan intensitas cahaya tinggi. ${ }^{2,3}$ Namun demikian beberapa jenis sirih mampu tumbuh sampai ketinggian lebih dari $1.000 \mathrm{~m} \mathrm{dpl}$.

Berdasarkan bentuk daun, rasa dan aromanya, sirih dibedakan menjadi beberapa jenis. Di Indonesia ada beberapa jenis sirih yang umum dikenal oleh masyarakat yaitu sirih jawa, sirig gading, sirih banda, sirih cengkih, dan sirih hitam atau sirih keling. Sirih jawa selain ditemukan di Jawa ditemukan juga di Maluku. Daun sirih jawa berwarna hijau tua dan rasanya tidak begitu tajam. Sirih Banda banyak tumbuh di Banda, Seram dan Ambon. Sirih Banda berdaun besar berwarna hijau tua dan kuning di beberapa bagian, rasa serta aroma atau baunya tajam. Sirih cengkih berdaun kecil, berwarna kuning dan rasanya sangat tajam biasanya digunakan untuk campuran obat. ${ }^{3}$ Dalam rangka standarisasi tentunya sangat dibutuhkan ketepatan dalam pemilihan jenis atau varietas sirih guna menjamin 
keajegan mutunya. Dalam rangka memberikan gambaran awal tentang botani dan kandungan minyak atsiri, maka dilakukan penelitian karakterisasi morfologi dan kandungan minyak atsiri beberapa jenis sirih yang dikenal oleh masyarakat.

\section{Metode}

\section{Bahan}

- Tanaman Sirih dengan jenis: cacing, hijau, gading, dan merah

- Toluene

- Etyl acetat

- Pereaksi vanilin asam sulfat

- Plate silika gel GF 254

- Penggaris dan kaca pembesar

\section{Desain dan waktu penelitian}

Penelitian dilakukan secara eksploratif dengan mengambil spesimen beberapa beberapa jenis sirih yang dikenal oleh masyarakat (gading, cacing, hijau dan merah), yang dilaksanakan pada bulan Januari-Februari 2015.

\section{Tempat penelitian}

Pengambilan spesimen dilakukan di daerah Jogjakarta (sirih gading), Mojosongo Surakarta (sirih cacing), dan di kebun koleksi B2P2TO2T (sirih hijau dan sirih merah).

\section{Cara pengambilan spesimen}

Pengambilan spesimen dilakukan dengan memotong dan mengumpulkan semua bagian tanaman selengkap mungkin yang terdiri dari tanaman utuh (akar, batang, daun, dan bunga) untuk keperluan karakterisasi, serta daun sebanyak $1 \mathrm{~kg}$ untuk keperluan destilasi minyak atsiri.

\section{Karakterisasi dan determinasi spesimen}

Spesimen tanaman utuh yang telah dikoleksi kemudian dikarakterisasi morfologi berdasarkan bentuk habitus, batang, perakaran, daun, dan bunga. Spesimen dideterminasi dan diidentifikasi jenisnya berdasarkan kunci determinasi Flora of Java (1965) untuk menentukan spesiesnya. ${ }^{4}$ Selanjutnya dilakukan pengamatan atas bentuk dan ukuran masing-masing bagian tanaman secara visual maupun dengan alat ukur (penggaris).

\section{Destilasi minyak atsiri}

Penetapan kadar dan profil minyak atsiri dilakukan guna memberikan gambaran secara kualitatif pertumbuhan dan hasil beberapa jenis sirih yang diambil dari beberapa daerah. Penetapan kadar minyak atsiri dilakukan dengan cara destilasi air (Stahl destilation), yaitu daun sirih segar ditumbuk kasar/dirajang, ditimbang masing-masing sebesar $100 \mathrm{~g}$, dimasukkan ke dalam labu alas bulat volume $1000 \mathrm{~mL}$. Tambahkan ke dalam labu alat bulat aquadest $500 \mathrm{~mL}$, goyang labu hingga bahan dan air bercampur. Pasang alat destilator dan isi buret dengan air, kemudian panaskan labu hingga penyulingan berlangsung dengan lambat tetapi teratur. Penyulingan dihentikan setelah tidak ada lagi penambahan volume minyak dalam buret, kemudian dibiarkan selama 15 menit dan catat volume minyak atsiri pada buret. Perhitungan kadar minyak dengan rumus:

$$
\mathrm{Ma}=\frac{\text { Vol minyak }}{\text { Berat bahan }} \times 100 \%
$$




\section{Profiling minyak atsiri}

Profiling minyak atsiri dilakukan dengan metode Kromatografi Lapis Tipis menggunakan fase diam Silika Gel G 60 F, dan fase bergerak Toluen: Etyl acetat= 93:7, penampak noda menggunakan vanilin asam sulfat. ${ }^{4}$ Hasil profiling kemudian didokumentasi untuk perhitungan nilai Rf masing-masing spot yang nampak pada plate KLT.

\section{Hasil dan Pembahasan}

Dari hasil pengumpulan spesimen yang dilaksanakan dari Jogjakarta ditemukan sirih Gading yang secara umum dikenal oleh masyarakat karena warna daunnya kuning. Spesimen sirih dari Mojosongo (Surakarta) berhasil dikoleksi jenis sirih Cacing yang dikenal masyarakat karena tipe pertumbuhan yang cenderung melata dan bukan memanjat. Dua spesimen sirih yang dikumpulkan dari kebun koleksi Balai Besar Litbang Tanaman Obat dan Obat Tradisional yaitu sirih hijau dan sirih merah. Ke-empat spesimen sirih selanjutnya dikarakterisasi dan diidentifikasi berdasarkan bentuk habitus, batang, daun, pembungaan, dan perakarannya. Hasil karakterisasi morfologi ke-empat spesimen sirih dapat dilihat pada Tabel 1.

Tabel 1. Diskripsi morfolongi sirih hijau, gading, cacing dan merah

\begin{tabular}{|c|c|c|c|c|c|}
\hline $\mathrm{N}$ & \multirow{2}{*}{$\begin{array}{c}\text { Bagian } \\
\text { Tanaman }\end{array}$} & \multicolumn{4}{|c|}{ Jenis sirih } \\
\hline o & & Sirih hijau & Sirih gading & Sirih cacing & Sirih merah \\
\hline 1. & Habitus & $\begin{array}{c}\text { Memanjat, } \\
\text { merayap, } \\
\text { panjang 1-3 m }\end{array}$ & $\begin{array}{c}\text { Memanjat, } \\
\text { merayap, } \\
\text { panjang 1-3 m }\end{array}$ & $\begin{array}{c}\text { Merayap, } \\
\text { sedikit } \\
\text { memanjat, } \\
\text { panjang 1-1,8 } \\
\text { m }\end{array}$ & $\begin{array}{c}\text { Memanjat, } \\
\text { merayap, panjang } \\
1-4 \mathrm{~m}\end{array}$ \\
\hline 2. & Batang & $\begin{array}{l}\text { Silindris, } \\
\text { beruas-ruas, } \\
\text { panjang antar } \\
\text { ruas } 7-20 \mathrm{~cm}, \\
\text { pada bagian } \\
\text { pangkal } \\
\text { mengayu, } \\
\text { beralur tegas, } \\
\text { hijau atau hijau } \\
\text { kekuningan. }\end{array}$ & $\begin{array}{l}\text { Silindris, } \\
\text { beruas-ruas, } \\
\text { panjang antar } \\
\text { ruas 6-16 cm, } \\
\text { pada bagian } \\
\text { pangkal } \\
\text { mengayu, } \\
\text { beralur tegas, } \\
\text { berbercak- } \\
\text { bercak putih, } \\
\text { berwarna ungu } \\
\text { kemerahan. }\end{array}$ & $\begin{array}{c}\text { Silindris, } \\
\text { beruas-ruas, } \\
\text { sedikit keras, } \\
\text { panjang antar } \\
\text { ruas } 4-15 \mathrm{~cm} \text {, } \\
\text { beralur, } \\
\text { halus, ungu } \\
\text { kecoklatan } \\
\text { sampai } \\
\text { kehitaman. }\end{array}$ & $\begin{array}{l}\text { Silindris, beruas- } \\
\text { ruas, panjang } \\
\text { antar ruas } 7-15 \\
\text { cm, pada bagian } \\
\text { pangkal mengayu, } \\
\text { beralur tegas, } \\
\text { berbercak bercak } \\
\text { keperakan, merah } \\
\text { keunguan. }\end{array}$ \\
\hline 3. & $\begin{array}{ll}\text { Daun } \\
\text { - } & \text { Jenis } \\
\text { - } & \text { Bentuk } \\
\text { - } & \text { Duduk daun } \\
- & \text { Panjang } \\
- & \text { Lebar } \\
\text { - } & \text { Tangkai } \\
& \text { daun } \\
\text { - } & \text { Tepi daun } \\
\text { - } & \text { Ujung daun }\end{array}$ & $\begin{array}{c}\text { Tunggal } \\
\text { Bulat telur } \\
\text { sampai lonjong } \\
\text { Berseling } \\
5-15 \mathrm{~cm} \\
2-10 \mathrm{~cm} \\
5-9 \mathrm{~cm} \\
\text { Rata } \\
\text { Meruncing } \\
\text { Membulat } \\
\end{array}$ & $\begin{array}{c}\text { Bersilang } \\
4-15 \mathrm{~cm} \\
2-10 \mathrm{~cm} \\
4-10 \mathrm{~cm} \\
\text { Rata } \\
\text { Meruncing } \\
\text { Membulat }\end{array}$ & $\begin{array}{l}\text { Tunggal } \\
\text { Bulat telur } \\
\text { Berseling } \\
3-10 \mathrm{~cm} \\
2-7 \mathrm{~cm} \\
3-7 \mathrm{~cm} \\
\text { Rata } \\
\text { Meruncing } \\
\text { Membulat }\end{array}$ & $\begin{array}{l}\text { Bulat telur sampai } \\
\text { lonjong } \\
\text { Berseling } \\
5-30 \mathrm{~cm} \\
2-22 \mathrm{~cm} \\
5-15 \mathrm{~cm} \\
\text { Rata } \\
\text { Meruncing } \\
\text { Membulat }\end{array}$ \\
\hline
\end{tabular}




\begin{tabular}{|c|c|c|c|c|c|}
\hline & $\begin{array}{ll}\text { - } & \text { Pangkal daun } \\
\text { - } & \text { Tulang daun } \\
\text { - } & \text { Aroma } \\
\text { - } & \text { Permukaan } \\
\end{array}$ & $\begin{array}{l}\text { Menyirip } \\
\text { Kuat } \\
\text { Halus, licin }\end{array}$ & $\begin{array}{l}\text { Menyirip } \\
\text { Kurang kuat } \\
\text { Halus, licin }\end{array}$ & $\begin{array}{l}\text { Menyirip } \\
\text { Kuat } \\
\text { Halus, licin }\end{array}$ & $\begin{array}{l}\text { Menyirip } \\
\text { Kurang kuat } \\
\text { Halus, licin }\end{array}$ \\
\hline 4. & Bunga & $\begin{array}{l}\text { Mejemuk, } \\
\text { bentuk bulir, } \\
\text { putih. }\end{array}$ & $\begin{array}{c}\text { Jarang } \\
\text { ditemukan }\end{array}$ & $\begin{array}{c}\text { Jarang } \\
\text { ditemukan }\end{array}$ & Jarang ditemukan \\
\hline 5. & $\begin{aligned} \text { Akar } & \\
- & \text { Tipe } \\
- & \text { Warna }\end{aligned}$ & $\begin{array}{c}\text { Akar panjat } \\
\text { Putih }\end{array}$ & $\begin{array}{c}\text { Akar panjat } \\
\text { Putih }\end{array}$ & $\begin{array}{l}\text { Akar panjat } \\
\text { Ungu } \\
\text { kemerahan }\end{array}$ & $\begin{array}{c}\text { Akar panjat, } \\
\text { muncul di antara } \\
\text { ruas batang, ungu } \\
\text { kemerahan }\end{array}$ \\
\hline
\end{tabular}

Dari Tabel 1 terlihat bahwa ke-empat spesimen memiliki karakter morfologi yang berbeda antara satu dengan yang lain. Karakterisasi morfologi dilakukan dengan mengamati secara langsung terhadap habitus, bentuk dan warna batang dan daun (Gambar 1 dan 2). Selanjutnya hasil karakterisasi dirujuk pada buku identifikasi tumbuhan. Hasil identifikasi botani diketahui bahwa sirih cacing, sirih hijau dan sirih gading memiliki nama botani Piper betle L. sedangkan sirih merah memilliki nama botani Piper crocatum L. atau Piper ornatum L. ${ }^{4}$

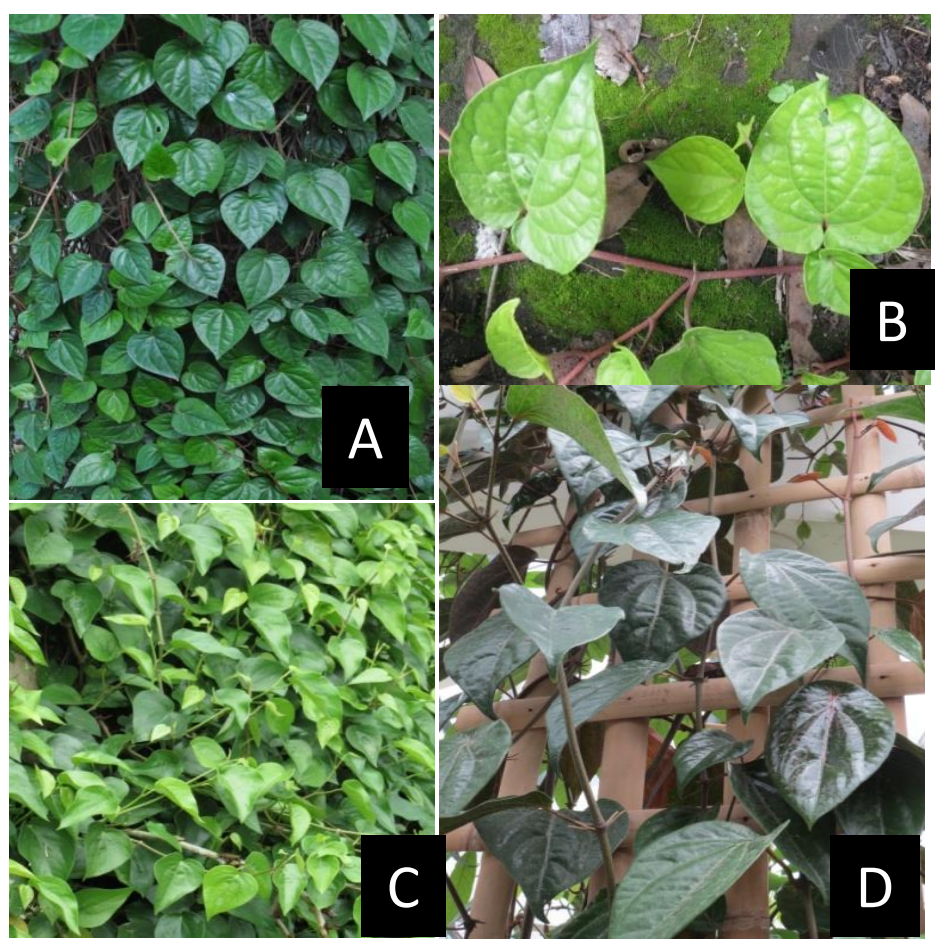

Gambar 1. Bentuk habitus empat jenis sirih; A. Sirih cacing, B: sirih gading; C: sirih hijau; D: sirih merah.

Perbedaan morfologi yang paling mudah dikenali dari ke-empat spesimen adalah pada bentuk habitus, warna batang, warna dan tekstur daun, warna tangkai daun dan 
aroma. Sirih cacing, sirih hijau dan sirih gading meskipun memiliki ciri ciri morfologi yang berbeda, namun dari kunci determinasi merujuk pada spesies yang sama yaitu Piper betle L. Hal ini dimungkinkan karena Piper betle L. memiliki berbagai varitas dan kultivar. Lakshmi dan Naidu (2010) menyebutkan bahwa di India terdapat lebih kurang 125 sampai 150 kultivar sirih ${ }^{[5]}$. Moeljanto (2003) menyebutkan berdasarkan bentuk daun, rasa dan aromanya, sirih dibedakan menjadi beberapa jenis. ${ }^{3}$ Pengenalan bentuk morfologi daun, warna dan aroma sangat penting untuk mengetahui jenis-jenis sirih. ${ }^{6}$

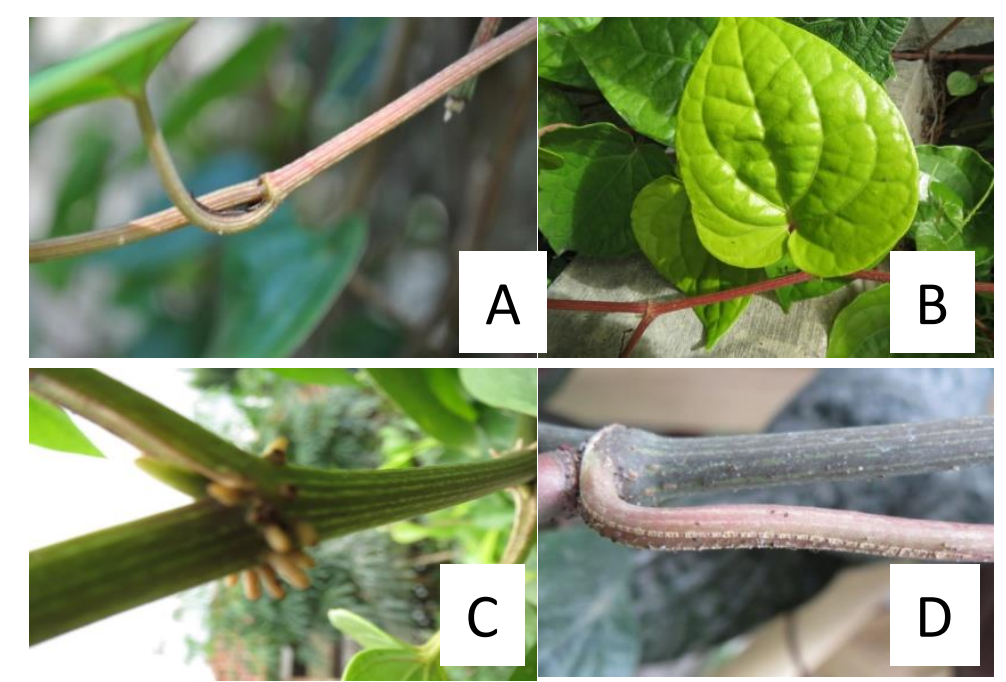

Gambar 2. Bentuk dan warna batang 4 jenis sirih; A: sirih cacing; B: sirih gading; C: sirih hijau; D: sirih merah

Untuk mengetahui apakah perbedaan morfologi jenis-jenis sirih tersebut juga berkaitan dengan perbedaan kandungan kimianya maka dilakukan ekstraksi minyak atsiri dan analisis kromatografi lapis tipis terhadap minyak yang dihasilkan. Kadar dan karakter organoleptis minyak atsiri masing-masing jenis sirih dapat dilihat pada Tabel 2.

Tabel 2. Kadar dan karakter secara organoleptis minyak atsiri beberapa jenis sirih

\begin{tabular}{lcc}
\hline \multicolumn{1}{c}{ Jenis Sirih } & Kadar & Organoleptis \\
\hline Sirih Hijau & $0,6 \%$ & Putih kekuningan, aroma kuat, rasa pahit pedas \\
Sirih Cacing & $0,3 \%$ & Kuning keemasan, aroma kuat, rasa pahit pedas \\
Sirih Gading & $0,3 \%$ & Kuning cerah, aroma lembut, rasa pahit pedas \\
Sirih Merah & $0,6 \%$ & Jernih, aroma lembut, rasa pahit \\
\hline
\end{tabular}

Dari Tabel 2 dapat diketahui bahwa kadar dan spesifikasi minyak atsiri masingmasing jenis sirih berbeda. Sirih hijau yang memiliki aroma paling kuat memiliki kadar minyak atsiri sebesar $0,6 \%$, sedang sirih cacing dan sirih gading memiliki kadar yang sama yaitu $0,3 \%$, untuk sirih merah meskipun aroma daunnya tidak terlalu kuat ternyata memiliki kandungan minyak atsiri yang cukup tinggi sebesar 0,6\%. Dari pengamatan organoleptis terhadap minyak atsiri, masing-masing jenis sirih memiliki spesifikasi minyak yang berbeda baik pada bau dan warna. 
Pradan (2013) menyebutkan bahwa kandungan utama minyak atsiri daun sirih adalah hydroksicavikal asetat (HCA), alilpirocatekol (APC), kavibetol (CHV), piperbetol, eugenol, carioplilen, carvakrol, dan lain-lain. ${ }^{7}$ Kavikol yang menyebabkan sirih berbau khas dan memiliki khasiat antibakteri lima kali lebih kuat daripada fenol serta immunomodulator. ${ }^{3}$ Hasil analisis Kromatografi Lapis Tipis yang dilakukan terhadap minyak atsiri 4 jenis sirih dapat dilihat pada Gambar 3.

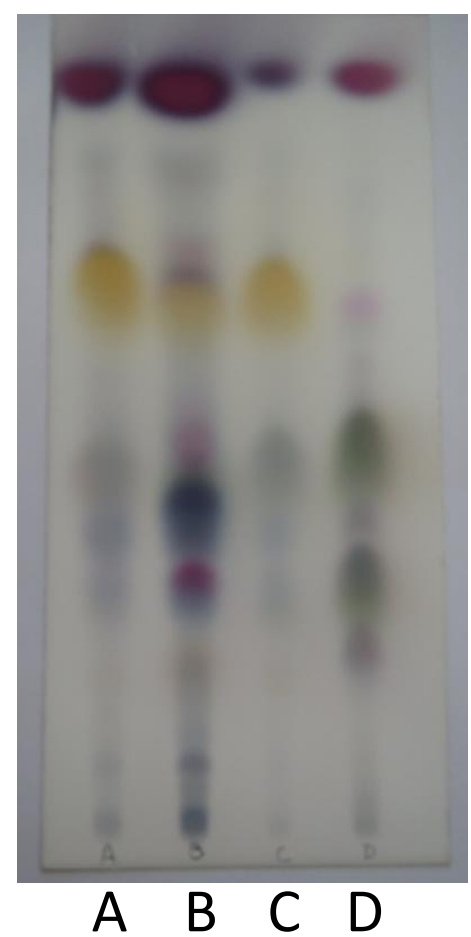

Gambar 3. Profil kromatogram minyak atsiri beberapa jenis sirih; A: Sirih cacing; B: Sirih gading; C: Sirih hijau; D: Sirih merah.

Dari hasil profiling secara KLT, diketahui bahwa terdapat perbedaan kandungan minyak atsiri empat jenis sirih baik dari jumlah komponen maupun kadar dari masingmasing komponen yang ditunjukkan dalam jumlah spot dan intensitas warna spot.

Dari gambar 3 diketahui bahwa jumlah spot dari hasil visualisasi KLT minyak atsiri empat jenis sirih terdapat jumlah spot antara 6 (sirih hijau) sampai 12 (sirih gading). Minyak atsiri sirih gading memiliki jumlah komponen paling banyak. Sirih cacing, hijau dan gading masing-masing memiliki spot yang sama pada Rf 0,11 berwarna kuning dan berdasarkan pustaka disebutkan sebagai eugenol. ${ }^{2}$ Eugenol, merupakan senyawa utama yang terkandung dalam daun sirih dan diketahui memiliki aktivitas anti-inflamasi pada beberapa model hewan coba. ${ }^{9}$

Sirih merah yang secara organoleptis tidak memberikan aroma kuat sirih dan tidak berasa pedas ternyata tidak memiliki spot eugenol. Sirih gading dan sirih hijau memiliki kesamaan dalam jumlah dan warna spot, dimungkinkan keduanya memiliki kandungan senyawa yang sama. Sirih gading dan sirih merah memiliki perbedaan jumlah dan warna spot dibandingkan dengan sirih hijau dan sirih cacing. Selain karena perbedaan jenis atau varitas, kandungan kimia suatu tanaman obat juga sangat kuat dipengaruhi oleh lingkungan tumbuhnya. ${ }^{8}$ Hasil preliminary profil minyak atsiri beberapa varitas sirih ini bisa digunakan sebagai acuan untuk standar bahan baku daun sirih di pasaran bebas. 


\section{Kesimpulan dan saran}

Dari penelitian yang telah dilakukan maka dapat disimpulkan bahwa perbedaan nyata masing-masing jenis sirih secara morfologi yang mudah diamati adalah pada bentuk habitus, batang, daun, serta aroma daun. Sirih cacing, sirih gading dan sirih hijau berdasarkan hasil identifikasi morfologi memiliki nama botani yang sama yaitu Piper betle L., sedang sirih merah adalah Piper crocatum L. Kadar minyak atsiri masing-masing jenis sirih berturut turut: sirih hijau $(0,6 \%)$, sirih cacing $(0,3 \%)$, sirih gading $(0,3 \%)$, dan sirih merah $(0,6 \%)$. Profil KLT dari minyak atsiri masing-masing jenis sirih menunjukkan perbedaan dalam jumlah spot maupun warna spot. Minyak atsiri sirih gading memiliki komponen paling banyak (12 spot) dan sirih hijau paling sedikit (7 spot). Untuk itu disarankan dilakukan penelitian lanjut terkait aktivitas farmakologi dari masing-masing jenis minyak atsiri serta identifikasi masing-masing jenis kandungan senyawa aktifnya.

\section{Ucapan terima kasih}

Penulis mengucapkan terima kasih kepada Kepala Balai Besar Litbang Tanaman Obat dan Obat Tradisional yang telah memberikan ijin sehingga penelitian ini bisa terlaksana.

\section{Daftar Pustaka}

1. Heyne, K. Tumbuhan berguna Indonesia Jilid II. Bogor: Badan Litbang Kehutanan, Departemen Kehutanan RI; 1987.

2. Wagner H, S Bladt, EM Zgainski. Plant drug analysis, a thin layer chromatography atlas. Berlin: Springer-Verlag., 1984.

3. Moeljanto R. Khasiat dan manfaat daun sirih, Jakarta: Agromedia Pustaka; 2003.

4. Backer CA and RC Bakhuizen van den Brink. Flora of Java (spermatophytes only), vol III. Groningen The Netherlands: Wolters-Noordhoff NV; 1968.

5. Lakshmi BS and Naidu KC. Comparative Morphoanatomy of Piper betle L., cultivars in India. Annals of Biological Research. 2010; 1(2): 128-134, diunduh dari www.scholarsresearchlibrary.com/ABR-vol1-iss2/ABR-2010-1-2-128-134.pdf pada tanggal 25 Maret 2015.

6. Raman V, Galal AM, and Khan IA. An Investigation of the vegetative anatomy of Piper sarmentosum, and a Comparison with the Anatomy of Piper betle (Piperaceae). American Journal of Plants Science. 2012; (3): 1135-1144, diunduh dari www.scirp.org/journal/PaperInformation.aspx?PaperID=22192\#:VXD.Z9Ltmko pada tanggal 25 Maret 2015.

7. Pradhan D, Suri KA, Pradhan DK and Biswasroy P. Golden heart of the nature: Piper betle L. Journal of Pharmacognosy and Phytochemistry. 2013; 1(6): 147-167; diunduh dari www.phytojournal.com/Vol1Issue6/Issue_march_2013/19.pdf pada tanggal 25 Maret 2015.

8. Manoj P Rai, Karadka RT, Princy LP, Prathima R, Suresh R., Harshith PB, MS Baliga,. Piper betle Linn (Betel Vine), the maligned Southeast Asian medicinal plants possesses cancer preventive effects: time to reconsider the wronged opinion. Asian Pacific Journal of Cancer Prevention, 2011; (12): 2149-2156, diunduh dari www.apocpcontrol.org/paper_file/Issue_abs/Volume12_No9/214956\%2067.24\%Baliga(1).pdf pada tanggal 25 Maret 2015.

9. Vandana Dwivedi and Shalini Tripathi. Review study on potential activity of Piper betle. Journal of Pharmacognosy and Pharmacology, 2014; 3(4): 93-98, diunduh dari http://www.phytojournal.com/vol3Issue4/Issue_nov_2014/17.1.pdf. 